\title{
Effects of taping therapy for carpal space expansion on electrophysiological change in patients with carpal tunnel syndrome
}

\author{
Yeong-Dong Park' , Yun-Jin Park', Sang-Seo Park', Hae-Lim Lee' ${ }^{1}$ Hyeong-Hun Moon², Myung-Ki Kim ${ }^{1} *$ \\ 'School of Global Sport Studies, Korea University, Sejong, Korea \\ 2Department of Sports Medicine, CHA University, Pocheon, Korea
}

Taping therapy is one of the most conservative treatments for carpal tunnel syndrome (CTS). Preceding research studied on pain control, grip strength, and wrist function but no studies have been reported on electrophysiolgical changes after taping therapy. The aim of this study is to evaluate the effects of taping therapy for carpal space expansion on electrophysiological in 20 female patients aged from 40 s to 60 s with CTS. Experimental group applied taping therapy for carpal space expansion twice a week for 4 weeks and control group did not. There were significant differences between distal motor latency (DML) and

\section{INTRODUCTION}

Carpal tunnel syndrome (CTS) is a common disease characterized peripheral entrapment neuropathy (Bland, 2007). Although the exact cause of disease is unknown, CTS is associated with a variety of diseases such as fracture and dislocation of wrist (Shin et al., 2012), diabetes (Pournmemari and Shiri, 2016), rheumatic arthritis (Shiri et al., 2015), hypothyroidism (Shiri, 2014).

Currently, diagnosis of CTS is based on clinical examination and various symptoms. However, this method is useful for initial diagnosis, but it cannot provide objective information about degree of demyelination and loss of axon (Jablecki et al., 1993). Therefore, electrophysiological examination using electromyogram is very useful because it provides accurate information on nerve function evaluation and nerve damage in median nerve. Also, it is able to diagnose without having definitely clinical symptom (Jablecki et al., 2002). sensory nerve conduction velocity (SNCV), but no difference between compound muscle action potential and sensory nerve action potential (SNAP) after 4 weeks taping treatment. Also, there was a significant difference in DML, SNCV, and SNAP in between groups. In conclusion, taping therapy for carpal space expansion can help to reduce the pressure of the carpal tunnel in CTS patients with mild symptoms.

Keywords: Carpal tunnel syndrome, Taping therapy, Electrophysiological change
Conservative therapy of CTS is applied when there is only mild symptom or conduction blockage. The representative method is to fix wrist movement using splinting and taping (Atroshi et al., 2013) or control symptoms using local corticosteroid injection (Atroshi et al., 2013). It's effective in reducing edema and pain in the short term but not persistent (Huisstede et al., 2010). In addition, specific females related side effects have been reported (Brook et al., 2017). The taping, which serves as a support for the wrist, pulls around the wrist to reduce excessive pressure on the carpal tunnel and induce proper relaxation (Lund and Amadiol, 2006).

However, preceding research in the taping application of CTS has proven pain control, functional evaluation of the wrist and grip strength of its effectiveness but the studies on the nerve conduction test of electrophysiological changes are still in a poor condition.

Therefore, the aim of this study is to evaluate the effect of taping therapy for carpal space expansion on electrophysiological changes in CTS patients who had mild symptom.
*Corresponding author: Myung-Ki Kim (iD http://orcid.org/0000-0002-5821-9203 School of Global Sport Studies, Korea University, Sejong Campus, 2511 Sejong-ro, Jochiwon-eup, Sejong 30019, Korea

Tel: +82-44-860-1366, Fax: +82-44-860-1589, E-mail: kmk1905@korea.ac.kr Received: May 22, 2017 / Accepted: June 16, 2017
This is an Open Access article distributed under the terms of the Creative Commons Attribution Non-Commercial License (http://creativecommons.org/licenses/by-nc/4.0/) which permits unrestricted non-commercial use, distribution, and reproduction in any medium, provided the original work is properly cited. 


\section{MATERIALS AND METHODS}

\section{Subjects}

We recruited 20 female patients, aged 40-60 years, who were diagnosed with CTS in a general hospital in Seoul, Korea. The symptoms included more than 3 months after the onset of symptoms (14 hands), and 10 nontreated subjects (12 hands) at random (Table 1). All patients agreed voluntarily before participating the experiment. The following subjects were excluded: (a) patients with multiple peripheral neuropathy, cervical myopathy, thoracic outlet syndrome, anterior synechiae syndrome, diabetes, thyroid disease, traumatic injury; (b) patients with severe CTS with atrophy of thenar muscle or muscular weakness; (c) Patients showing skin redness when taping was applied in the pilot study.

\section{Electrophysiological examination}

The median motor nerve conduction test was performed using the EMG system (Cadwell Sierra wave, Cadwell, Kennewick, WA, USA) and applied the belly tendon method. Active electrode was attached to the belly if the abductor pollicis brevis and reference electrode was attached to the tendon to record the compound muscle action potential (CMAP) and measured the distal motor latency (DML), amplitude and conduction velocity by section. Median sensory nerve conduction test applied orthodrmoic meth-

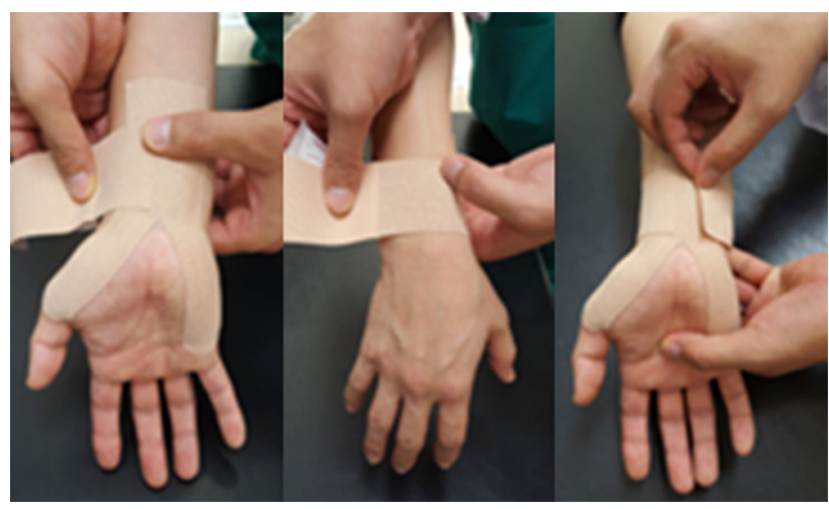

Fig. 1. Muscle taping. od by Oh method. The active electrode was attached between the flex or carpiradialis at the center of the wrist and the tendon of the palmaris longus. The reference electrode was attached 3 to $4 \mathrm{~cm}$ below the active electrode and measured DML, amplitude and conduction velocity by section by measuring the maximal phase stimulus at the metacarpophalangeal joint of the second finger.

\section{Taping therapy for carpal space expansion}

The tape was attached with a Y-shaped kinesio tape $5 \mathrm{~cm}$ in width and $20-25 \mathrm{~cm}$ in length, removed after $48 \mathrm{hr}$ and reapplied after a $24 \mathrm{hr}$ of rest period considering skin eruption. Muscle taping, correction taping, and carpal taping were performed (Figs. 1-3).

\section{Statistical analysis}

The mean and standard deviation of the variables were calculated and a paired t-test was performed to determine the significance level in the group of and electrophysiological changes, before and after the taping treatment for space expansion. An independent t-test was conducted to determine the significance level between groups. IBM SPSS Statistics ver. 21.0 (IBM Co., Armonk, NY,

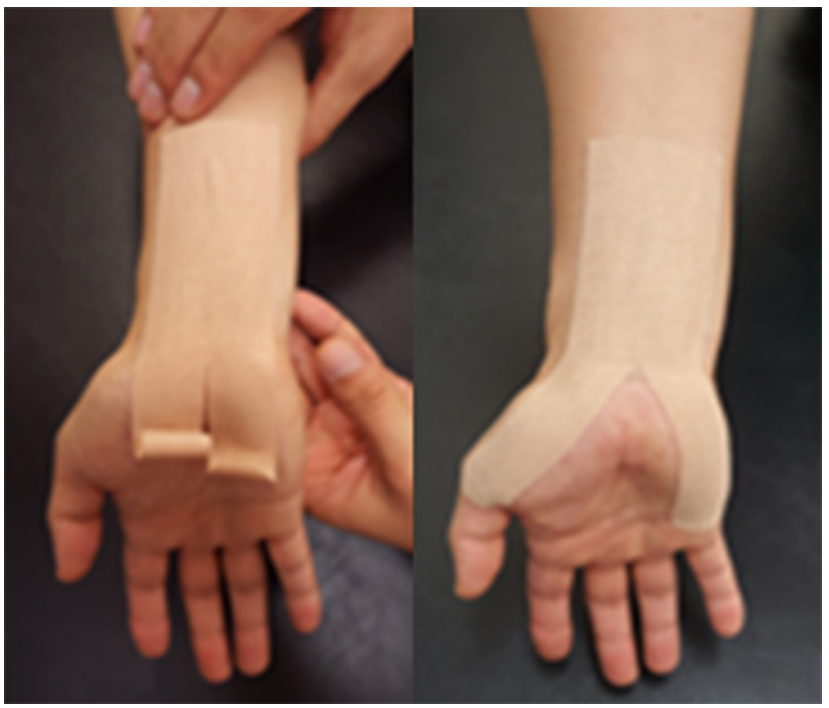

Fig. 2. Expansion taping.

Table 1. Physical characteristics of subjects

\begin{tabular}{|c|c|c|c|c|c|c|c|}
\hline \multirow{2}{*}{ Group } & \multirow{2}{*}{ Age (yr) } & \multirow{2}{*}{ Weight (kg) } & \multirow{2}{*}{ Height (cm) } & \multirow{2}{*}{$\begin{array}{l}\text { Time since onset } \\
\text { (mo) }\end{array}$} & \multicolumn{3}{|c|}{ Affected side } \\
\hline & & & & & Right & Left & Both \\
\hline $\mathrm{EG}(\mathrm{n}=10)$ & $50.50 \pm 5.58$ & $58.70 \pm 6.68$ & $156.30 \pm 4.71$ & $9.92 \pm 5.70$ & 4 & 2 & 4 \\
\hline$C G(n=10)$ & $49.80 \pm 6.66$ & $62.50 \pm 6.62$ & $152.80 \pm 5.30$ & $9.41 \pm 6.28$ & 6 & 2 & 2 \\
\hline
\end{tabular}

Values are presented as mean \pm standard deviation.

$\mathrm{EG}$, exercise group; $\mathrm{CG}$, control group. 
USA) was employed for the analysis of all the collected data, and the level for verifying statistical significance was set at $\alpha=0.05$.

\section{RESULTS}

\section{Changes of motor nerve conduction after taping therapy Changes of DML}

As shown in Fig. 4, EG showed statistically significant difference compared to 4 weeks before $(P<0.001)$, but $C G$ showed no significant difference compared to 4 weeks before, and statistically

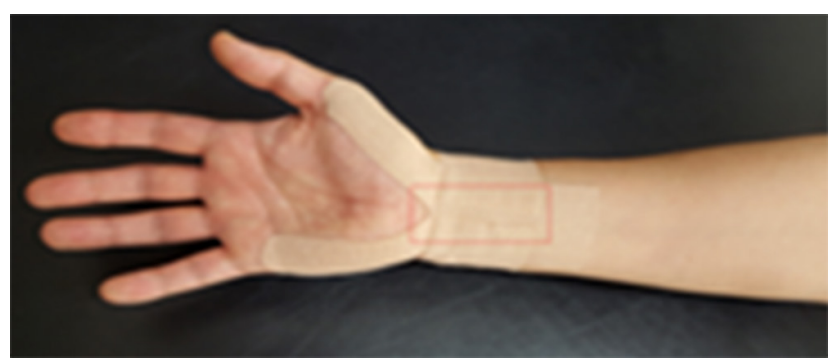

Fig. 3. Carpel tunnel taping.
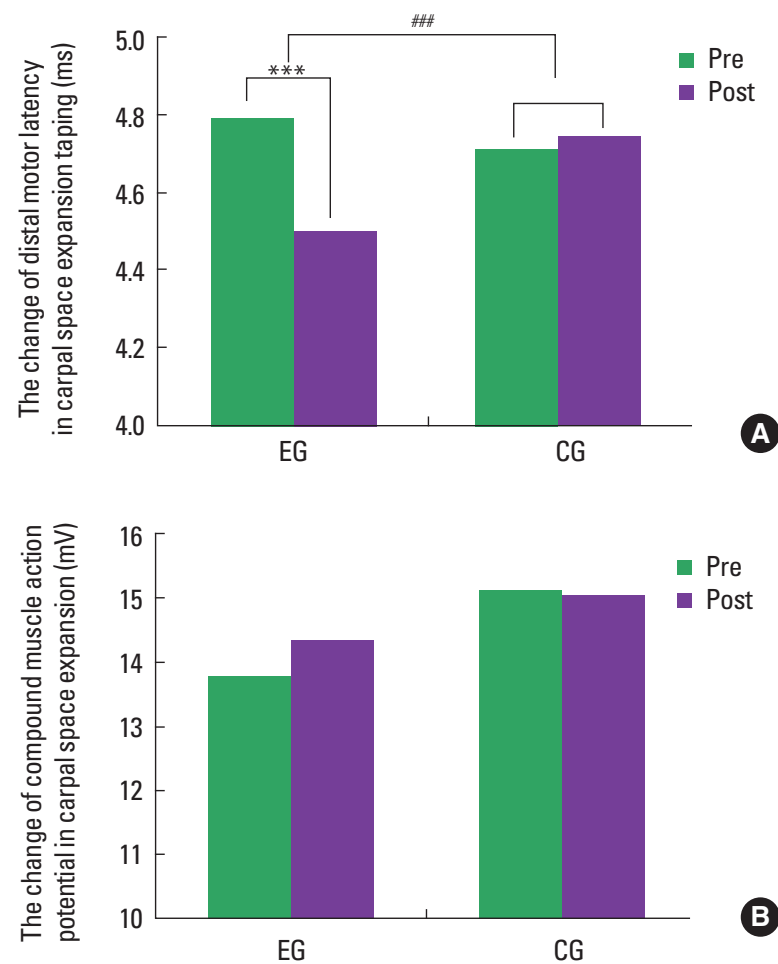

Fig. 4. The change of motor nerve conduction after taping therapy. (A) Distal motor latency. (B) Compound muscle action potential. EG, experimental group; CG, control group. ${ }^{* *} P<0.001$, difference of time in group. ${ }^{\# \#} P<0.001$, difference of groups in post. significant difference between groups $(P<0.001)$

\section{Changes of CMAP}

Both EG and CG were no statistically significant difference compared to 4 weeks before, and there was no significant difference between groups.

\section{Changes of sensory nerve conduction after taping therapy \\ Changes of SNCV}

Fig. 5 showed the change of 4 weeks sensory nerve conduction. EG showed statistically significant difference compared to 4 weeks before $(P<0.001)$, but $\mathrm{CG}$ showed no significant difference compared to 4 weeks before, and statistically significant difference between groups $(P<0.001)$.

\section{Changes of SNAP}

Both EG and CG were no statistically significant difference compared to 4 weeks before, and there was statistically significant difference between groups $(P<0.05)$.
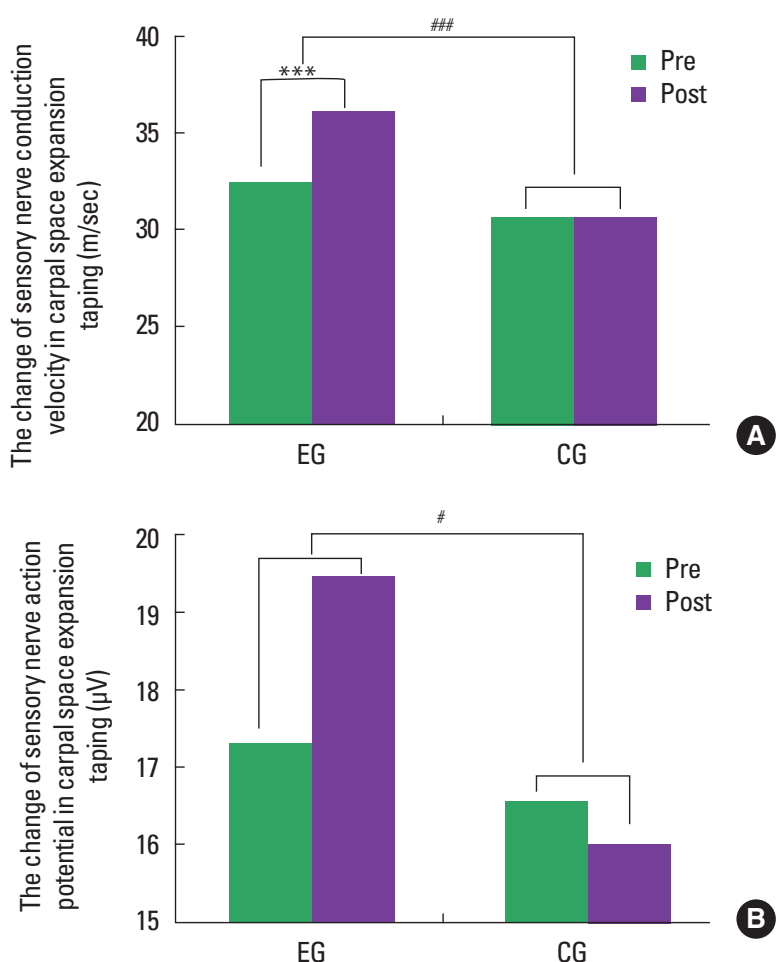

Fig. 5. The change of sensory nerve conduction after taping therapy. (A) Sensory nerve conduction velocity. (B) Sensory nerve action potential. EG, experimental group; $\mathrm{CG}$, control group. ${ }^{* *} P<0.001$, difference of time in group. ${ }^{*} P<$ $0.05,{ }^{\# \#} P<0.001$, difference of groups in post. 


\section{DISCUSSION}

Because CTS patient with mild symptom are often neglected without any treatment, the symptoms become worse, wrist pain, and hypoesthesia appeared regularly with time. The advantage of this study was to evaluate electrophysiological change by taping applied to CTS patients who had irregular mild pain.

In this study, DML and SNCV of the median nerve showed statistically significant difference after 4 weeks space extension taping application. It means that the length of delayed the DML was shortened and the velocity of SNCV was faster. However, SNCP and CMAP showed no significant difference compared to before taping therapy. Also, except for the CMAP, DML, SNCV, and SNAP showed statistically significant differences between the groups. These results indicate that taping therapy for carpal space expansion has an effect of improving carpal tunnel release and reducing the excessive pressure of the carpal tunnel.

In the electrophysiological testing, DML and SNCV improved significantly after carpal tunnel decompression, but other indicators were not improved or changed (Longstaff et al., 2001; Tahririan et al., 2012). DML and SNCV are the fastest indicators of improvement in median nerve and important indicator in clinical practice. This changes result from axon regeneration after remyelination of the myelin sheath.

In this study, there was no significant difference between CMAP and SNAP in EG because of CTS patient who had mild symptoms without loss of action potential. Therefore, the amplitude of CMAP before taping treatment was in the normal range, suggesting that the difference was not statistically significant.

In conclusion, taping therapy for carpal space expansion resulted in electrophysiological change by reducing the pressure of the carpal tunnel and improving the damaged median nerve. Therefore, it might helpful to prevent progression to severe stage if it is properly performed as an early preventive method in mild CTS.

\section{CONFLICT OF INTEREST}

No potential conflict of interest relevant to this article was reported.

\section{REFERENCES}

Atroshi I, Flondell M, Hofer M, Ranstam J. Methylprednisolone injections for the carpal tunnel syndrome: a randomized, placebo-controlled trial. Ann Intern Med 2013;159:309-317.

Bland JD. Carpal tunnel syndrome. BMJ 2007:335:343-346.

Brook EM, Hu CH, Kingston KA, Matzkin EG. Corticosteroid injections: a review of sex-related side effects. Orthopedics 2017;40:e211-215.

Huisstede BM, Hoogvliet P, Randsdorp MS, Glerum S, van Middelkoop M, Koes BW. Carpal tunnel syndrome. Part I: effectiveness of nonsurgical treatments--a systematic review. Arch Phys Med Rehabil 2010; 91:981-1004.

Jablecki CK, Andary MT, Floeter MK, Miller RG, Quartly CA, Vennix MJ, Wilson JR; American Association of Electrodiagnostic Medicine; American Academy of Neurology; American Academy of Physical Medicine and Rehabilitation. Practice parameter: Electrodiagnostic studies in carpal tunnel syndrome. Report of the American Association of Electrodiagnostic Medicine, American Academy of Neurology, and the American Academy of Physical Medicine and Rehabilitation. Neurology 2002;58:1589-1592.

Jablecki CK, Andary MT, So YT, Wilkins DE, Williams FH. Literature review of the usefulness of nerve conduction studies and electromyography for the evaluation of patients with carpal tunnel syndrome. AAEM Quality Assurance Committee. Muscle Nerve 1993;16:1392-1414.

Longstaff L, Milner RH, O'Sullivan S, Fawcett P. Carpal tunnel syndrome: the correlation between outcome, symptoms and nerve conduction study findings. J Hand Surg Br 2001;26:475-480.

Lund AT, Amadio PC. Treatment of cubital tunnel syndrome: perspectives for the therapist. J Hand Ther 2006;19:170-178.

Pourmemari MH, Shiri R. Diabetes as a risk factor for carpal tunnel syndrome: a systematic review and meta-analysis. Diabet Med 2016;33: 10-16.

Shin CH, Paik NJ, Lim JY, Kim TK, Kim KW, Lee JJ, Park JH, Baek GH, Gong HS. Carpal tunnel syndrome and radiographically evident basal joint arthritis of the thumb in elderly Koreans. J Bone Joint Surg Am 2012;94:e1201-1206.

Shiri R. Hypothyroidism and carpal tunnel syndrome: a meta-analysis. Muscle Nerve 2014;50:879-883.

Shiri R, Pourmemari MH, Falah-Hassani K, Viikari-Juntura E. The effect of excess body mass on the risk of carpal tunnel syndrome: a meta-analysis of 58 studies. Obes Rev 2015;16:1094-1104.

Tahririan MA, Moghtaderi A, Aran F. Changes in electrophysiological parameters after open carpal tunnel release. Adv Biomed Res 2012;1:46. 